\title{
Effect of N-Acetylcysteine on the Matrix Metalloproteinases and Their Inhibitors in Carbon Tetrachloride-Induced Hepatotoxicity
}

\author{
Kamalakkannan $\mathrm{N}^{1 \dagger}$, Khalid S. Al-Numair ${ }^{2}$, Abdullah H. Al-Assaf ${ }^{2}$, Ali A. Al-Shatwi ${ }^{2}$, and Menon VP $^{1}$ \\ ${ }^{1}$ Department of Biochemistry and Biotechnology, Annamalai University, Annamalainagar-608002, Tamilnadu, India \\ ${ }^{2}$ Department of Food Sciences and Nutrition, College of Food and Agricultural Sciences, \\ King Saud University, Riyadh-11451, Saudi Arabia
}

\begin{abstract}
Matrix metalloproteinases (MMPs) are a group of zinc proteases that serve the function of breaking down extracellular matrix (ECM). The present study evaluated the role of N-acetylcysteine (NAC) on the increased deposition of ECM in hepatic and glomenular fibrosis caused by carbon tetrachlonide $\left(\mathrm{CCl}_{4}\right)$. The activity of MMPs increased and the levels of tissue inhibitors of metalloproteinases 1 and 2 (TIMP-1 and TIMP-2) decreased in the liver and kidney of $\mathrm{CCl}_{4}$-treated rats. Rats treated with $\mathrm{CCl}_{4}$ and $\mathrm{NAC}$ showed increased activities of MMPs and decreased levels of TIMP-1 and TIMP-2 in the liver and kidney. Treatment with NAC resulted in the effective degradation of ECM due to an increase in the activities of MMPs and a decrease in the levels of TIMPs.
\end{abstract}

Key words: matrix metalloproteinases, carbon tetrachloride, N-acetylcysteine, Wistar rats, liver, kidney

\section{INTRODUCTION}

Carbon tetrachloride $\left(\mathrm{CCl}_{4}\right)$-induced rats are highly useful as experimental models for the study of certain hepatotoxic effects (1). $\mathrm{CCl}_{4}$ at low quantity is responsible for the appearance of reversible lesions in the liver that occur in all subjects exposed at certain doses of the substance (2). $\mathrm{CCl}_{4}$ metabolism begins with the formation of the trichloromethyl free radical, $\mathrm{CCl}_{3}{ }^{\circ}$ through the action of the mixed function cytochrome P450 oxygenase system of the endoplasmic reticulum (3). The $\mathrm{CCl}_{3}$ radical reacts with various biologically important substances such as amino acids, nucleotides, and fatty acids, as well as proteins, nucleic acids, and lipids (4). In the presence of oxygen, the $\mathrm{CCl}_{3}{ }^{\circ}$ radical is converted to the trichloromethyl peroxy radical $\left(\mathrm{CCl}_{3} \mathrm{OO}{ }^{\circ}\right)$. This radical is more reactive and is capable of abstracting a hydrogen from polyunsaturated fatty acids (PUFA) and initiates the process of lipid peroxidation (5).

Extracellular matrix (ECM) plays an important role in the regulation of cell function and changes in its composition and structure could have a profound patho-physiological implication (6). Various types of collagens, laminin, fibronectin, and sulfated proteoglycans are the normal components of glomerular matrix (7). Excessive accumulation of the ECM proteins and modification of the liver architecture are major patho-histological features of the liver disease progression and are closely related to the action of MMPs (8). An imbalance between synthesis and degradation of these matrix components is closely associated with the accumulation of ECM within the glomerulus and subsequent progression of renal diseases (9).

Extracellular matrix degradation is controlled primarily by matrix metalloproteinases (MMPs). MMPs are a family of zinc-dependent proteases that degrade ECM proteins and are essential for cellular migration and tissue remodeling under physiological and pathological conditions (10). MMPs are synthesized as latent proenzymes, which are later activated by serine proteases, including trypsin and plasmin, active MMP-2 and membrane type-MMPs (11).The activity of MMPs is tightly regulated by tissue inhibitors of MMPs (TIMPs). TIMPs are $21 \sim 28 \mathrm{kD}$ proteins with a highly conserved sequence of six intramolecular disulfide bonds (12). TIMPs form physiologically irreversible complexes with all types of activated MMPs (13). MMPs have been proposed as important factors driving fibrosis in the liver and glomerulus. MMP-2 and MMP-9 belong to the type IV collagenase family and are responsible for the degradation of collagen type IV, V, VII, elastin, and fibronectin (14). Antioxidant compounds have been shown beneficial on matrix remodeling by maintaining MMPs/ TIMPs equilibrium in hepatic fibrosis $(15,16)$.

N-acetylcysteine (NAC) contains free sulfhydryl groups and it may directly react with electrophilic compounds such as free radicals (17). Miesel and Zuber (18) have reported that NAC contributes significantly to the

${ }^{\dagger}$ Corresponding author. E-mail: kamalnk@gmail.com

Phone: +91-4342-255925, Fax: +91-4342-255925 
intracellular antioxidant defense system by acting as a powerful consumer of superoxide, singlet oxygen and hydroxyl radicals. NAC could significantly interfere with the pathophysiology of free radical producing drug induced oxidative stress (19). Several reports have shown that NAC treatment protects against acetaminophen hepatotoxicity in patients (20) and in rats $(21,22)$.

The purpose of the present study is to assess the impact of NAC on the activities of MMPs (MMP-2 and MMP-9) and the levels of their inhibitors (TIMP-1 and TIMP-2) in liver and kidney in $\mathrm{CCl}_{4}$-induced hepatotoxicity in rats.

\section{MATERIALS AND METHODS}

\section{Expenimental animals}

Male albino Wistar rats of body weight $150 \sim 180 \mathrm{~g}$ were obtained from the Central Animal House, Rajah Muthiah Medical College and Hospital, Annamalai University and were maintained there. The rats were housed in polypropylene cages lined with husk. They were fed on a standard pellet diet (Agro Corporation Private Ltd., Bangalore, India) and water ad libitum.

\section{Chemicals}

$\mathrm{N}$-acetyl cysteine, tris, acrylamide, bis-acrylamide, gelatin, sodium dodecyl sulphate (SDS), ammonium persulfate, o-dianisidine, and 2,4,6-trinitrobenzene sulfonic acid (TNBS) were obtained from Sigma Chemical Company (St. Louis, MO, USA). $\mathrm{CCl}_{4}$ was purchased from Merck Ltd. (Mumbai, India). All other chemicals used in our study were of high analytical grade.

\section{Experimental design}

In our study, a total of 24 rats were used. The rats were divided into 4 groups of 6 rats each. NAC was orally administered to rats daily at a dose of $150 \mathrm{mg} / \mathrm{kg}$ body weight for three months using an intragastric tube. $\mathrm{CCl}_{4}$ was subcutaneously injected to rats at a dose of $3 \mathrm{~mL} / \mathrm{kg}$ body weight/week for three months.

\section{Group I Normal control rats}

Group II Normal rats orally administered with NAC $(150 \mathrm{mg} / \mathrm{kg}$ body weight/daily) (23)

Group III Rats subcutaneously injected with $\mathrm{CCl}_{4}(3 \mathrm{~mL} / \mathrm{kg}$ body weight/week $)$ (24)

Group IV Rats orally administered with NAC (150 mg/kg body weight/daily) along with subcutaneous injection of $\mathrm{CCl}_{4}$ ( $3 \mathrm{~mL} / \mathrm{kg}$ body weight/week).

The experiment was carried out for a period of three months. All the experimental protocols were approved by the Ethical Committee of Annamalai University. After the last treatment, the animals were fasted overnight and sacrificed by cervical dislocation.

\section{Tissue preparation}

Liver and kidney were dissected out immediately from rats, cleared off blood and stored in ice-cold containers containing phosphate buffered saline (PBS) with protease inhibitors. The tissues were washed with PBS and weighed. A known amount of the tissue was homogenized with $0.9 \% \mathrm{NaCl}$ and the homogenate was used for estimation of MMPs and TIMPs.

\section{Biochemical estimations}

Estimation of MMPs: The total activities of MMPs were assessed by multiwell zymography as described by Sudhakaran and Ambili (25). About 50 100 $\mu \mathrm{L}$ of the sample was added to the wells of a multiwell plate. Gelatin was added to standard Laemmli acrylamide polymerization mixture, at a final concentration of 1.0 $\mathrm{mg} / \mathrm{mL}$ under non-reducing conditions. This was added quickly into each well and allowed to set. After the gel was polymerized, the gel gently was detached from the bottom of the well and incubated with Tris- $\mathrm{HCl}$ solution $\left(0.05 \mathrm{M}, \mathrm{pH} 7.0 / 5 \mathrm{mM} \mathrm{CaCl}_{2}\right)$ for $36 \mathrm{hr}$. Each gel bit was then stained using coomassie blue and destained in water. The activity was determined using a laser densitometer.

Individual MMP expression was analyzed by gelatin zymography (26). Gelatin was added to standard Laemmli acrylamide polymerization mixture at a final concentration of $1.0 \mathrm{mg} / \mathrm{mL}$ under non-reducing condition. Concentrated tissue extract was mixed with 3:1 with substrate gel sample buffer and $20 \sim 30 \mu \mathrm{L}$ were loaded immediately into Laemmli acrylamide stacking gel on a mini gel. Gels were run at $15 \mathrm{~mA} / \mathrm{gel}$ while stacking and at $20 \mathrm{~mA} / \mathrm{gel}$ during the separating phase at $4^{\circ} \mathrm{C}$. Following electrophoresis, the gels were soaked in $2.5 \%$ Triton X-100 with gentle shaking at room temperature for 30 min with one change of detergent solution. Gel was rinsed and incubated overnight at $37^{\circ} \mathrm{C}$ in Tris/ $\mathrm{HCl}$ $\left(0.05 \mathrm{M}, \mathrm{pH} 7.5 / 5 \mathrm{mM} \mathrm{CaCl}_{2}\right)$. The gel was then stained using Coomassie blue and destained in water. The activity was determined using a laser densitometer.

MMP-2 and MMP-9 were estimated by succinylation method described by Baragi et al. (27). Densitometric analysis was carried out using Gel/Chemi Doc, Bio-Rad software 4.4.1. Gelatin was dissolved in $50 \mathrm{mM}$ borate buffer $(\mathrm{pH} 8.5)$ at a concentration of $20 \mathrm{mg} / \mathrm{mL}$. An equal amount of succinic anhydride was then gradually added to the solution and the $\mathrm{pH}$ of the reaction was maintained at 8.0 to 8.5 by the addition of $1.0 \mathrm{M} \mathrm{NaOH}$. 
The succinylated gelatin was then dialyzed extensively against $50 \mathrm{mM}$ sodium borate buffer, $\mathrm{pH}$ 8.5. All assays were done in 96 well flat bottom microtitre plates. MMP-2 was assayed in $50 \mathrm{mM}$ borate buffer ( $\mathrm{pH} 7.0$ ) with $10 \mathrm{mM} \mathrm{CaCl}_{2}$, whereas MMP-9 was assayed in 50 $\mathrm{mM}$ borate buffer $(\mathrm{pH} 8.5)$. The total reaction volume was $150 \mu \mathrm{L}$ which contained enzyme and $200 \mu \mathrm{g}$ of succinylated gelatin. Blank without substrate but with appropriate buffer and enzyme was performed for each enzyme assay. The reaction was carried out at $37^{\circ} \mathrm{C}$ for $30 \mathrm{~min}$. Fify $\mu \mathrm{L}$ of $0.3 \%$ TNBS was then added to the reaction mixture and incubated at room temperature for $20 \mathrm{~min}$. The optical density was determined at $420 \mathrm{~nm}$. The activities of MMP-2 and MMP-9 are expressed as the absorbance at $420 \mathrm{~nm} / \mathrm{min} / \mathrm{mg}$ protein.

Estimation of TIMPs: The levels of TIMPs were estimated by ELISA method as described by Iype et al. (28). $100 \mu \mathrm{L}$ of tissue homogenate was coated in different wells in 24 well ELISA plate. They were incubated at room temperature for $3 \mathrm{hr}$. After incubation, the wells were drained and washed with PBS twice. Then added $200 \mu \mathrm{L}$ of $0.05 \%$ tween- 20 and incubated at room temperature for $1 \mathrm{hr}$. It was washed with $0.05 \%$ tween- 20 in PBS twice. Added $100 \mu \mathrm{L}$ of primary antibody and incubated at room temperature for $2 \mathrm{hr}$. It was washed in tween-20 twice. Then added secondary antibody coupled to horseradish peroxidase and kept at room temperature for $1 \mathrm{hr}$. It was washed again with tween-PBS followed by PBS twice. Then added $1.0 \mathrm{~mL}$ of o-dianisidine to all the wells and incubated in dark for 30 min. The reaction was arrested by adding $5 \mathrm{~N} \mathrm{HCl}$ and the optical density was measured at $450 \mathrm{~nm}$. The levels of TIMP-1 and TIMP-2 were expressed as the absorbance at $450 \mathrm{~nm} / \mathrm{min} / \mathrm{mg}$ protein.

\section{Statistical analysis}

Statistical analysis was performed using one way analysis of variance (ANOVA) followed by Duncan's multiple range test. The values are mean of 6 rats for each group and $\mathrm{p}<0.05$ was considered as being statistically significant.

\section{RESULTS}

The total MMP activities of liver and kidney samples in rats treated with $\mathrm{CCl}_{4}$ and with NAC are shown in Fig. 1 and 2 and the densitometric readings are shown in Fig. 1a and 2a. In $\mathrm{CCl}_{4}$-treated rats, the total MMP activities were decreased. Administration of NAC to $\mathrm{CCl}_{4}$-treated rats increased the MMP activities. In normal+NAC treated rats, a normal pattern of multiwell zymography and relative densitometric reading was

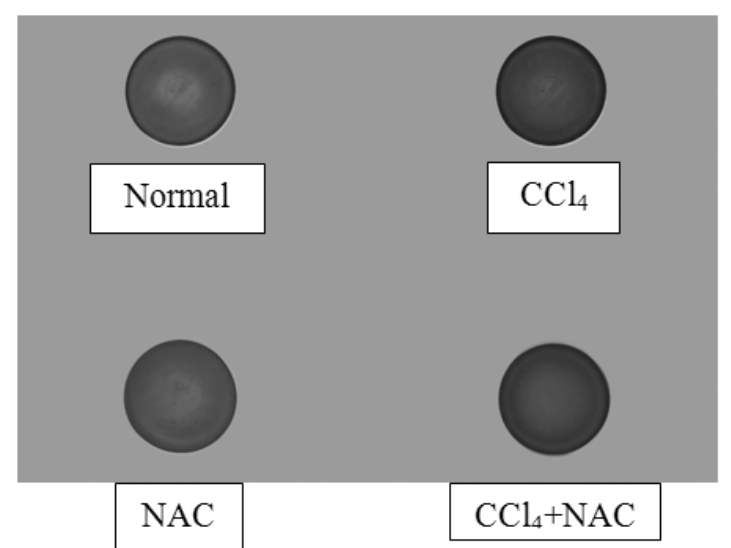

Fig. 1. Zymogram of liver samples during NAC treatment in $\mathrm{CCl}_{4}$ toxicity.

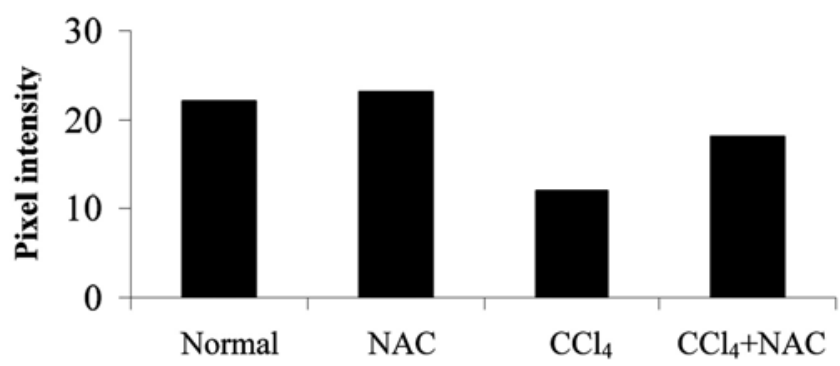

Fig. 1a. Densitometry of multiwell zymogram of liver samples during NAC treatment in $\mathrm{CCl}_{4}$ toxicity.

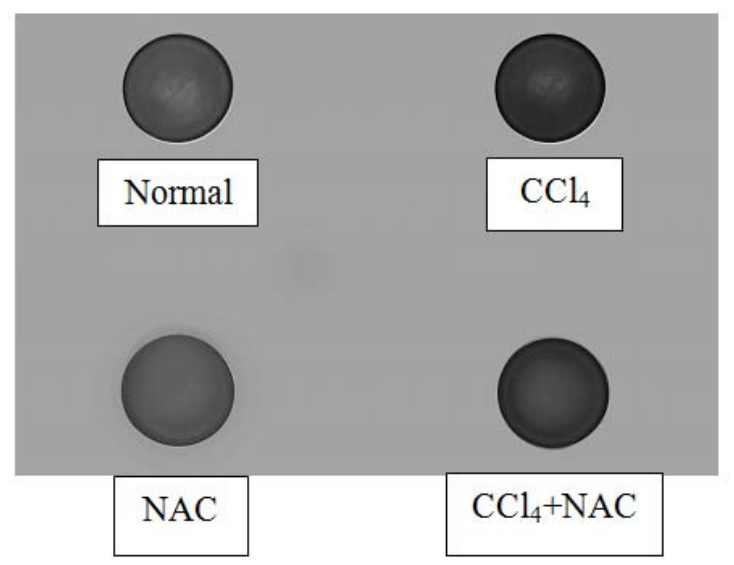

Fig. 2. Zymogram of kidney samples during NAC treatment in $\mathrm{CCl}_{4}$ toxicity.

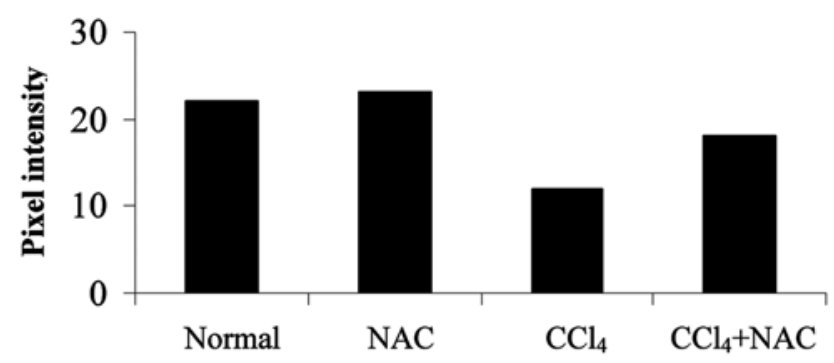

Fig. 2a. Densitometry of multiwell zymogram of kidney samples during $\mathrm{NAC}$ treatment in $\mathrm{CCl}_{4}$ toxicity. 


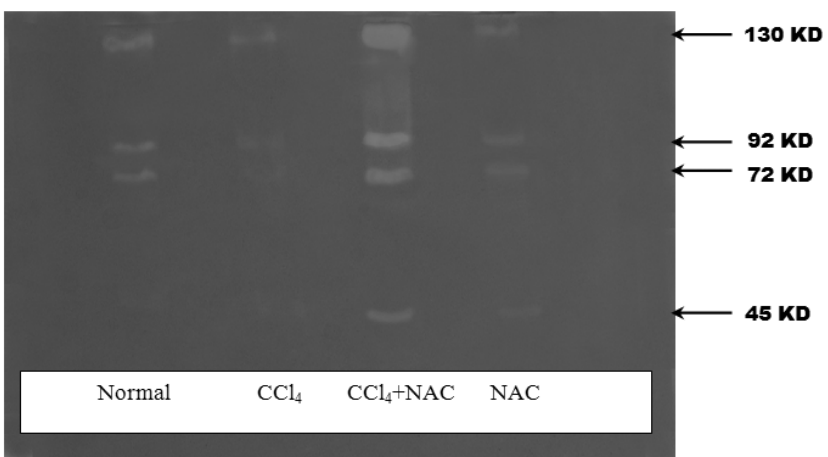

Fig. 3. Zymogram of liver samples during NAC treatment in $\mathrm{CCl}_{4}$ toxicity.

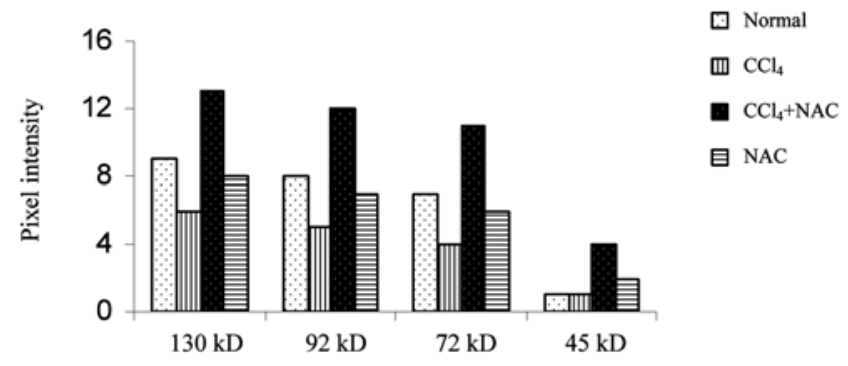

Fig. 3a. Densitometry of multiwell zymogram of liver samples during NAC treatment in $\mathrm{CCl}_{4}$ toxicity.

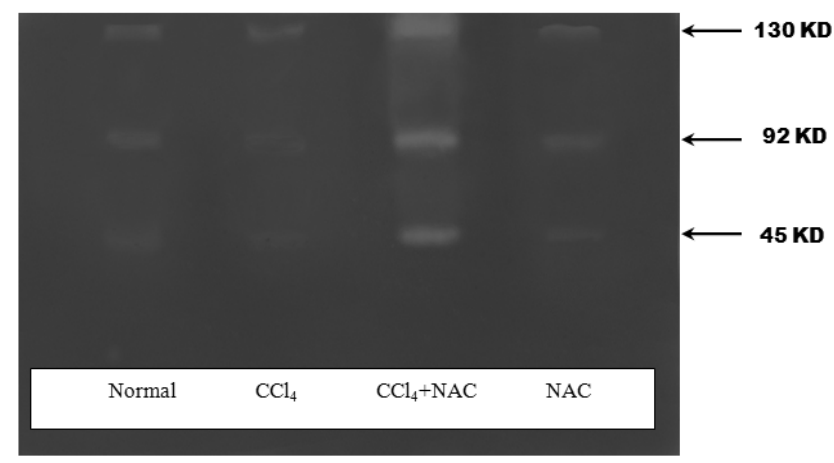

Fig. 4. Zymogram of kidney samples during NAC treatment in $\mathrm{CCl}_{4}$ toxicity.

obtained.

Gelatin zymograms of liver and kidney samples from rats treated with $\mathrm{CCl}_{4}$ and with NAC are shown in Fig. 3 and 4, respectively. Four different types of MMPs (130 $\mathrm{kD}, 92 \mathrm{kD}, 72 \mathrm{kD}$, and $45 \mathrm{kD}$ ) were expressed in liver and three different types of MMPs $(130 \mathrm{kD}, 92 \mathrm{kD}$, and $72 \mathrm{kD}$ ) were expressed in kidney of rats, during $\mathrm{CCl}_{4}$ administration and subsequent treatment with NAC. The densitometric reading of the individual MMPs are given in Fig. 3a and 4a, respectively. The activities of MMPs were decreased in $\mathrm{CCl}_{4}$-treated rats. When these rats were treated with NAC, there was an increase in the MMP activities.

The levels of TIMPs (TIMP-1 and TIMP-2) in liver

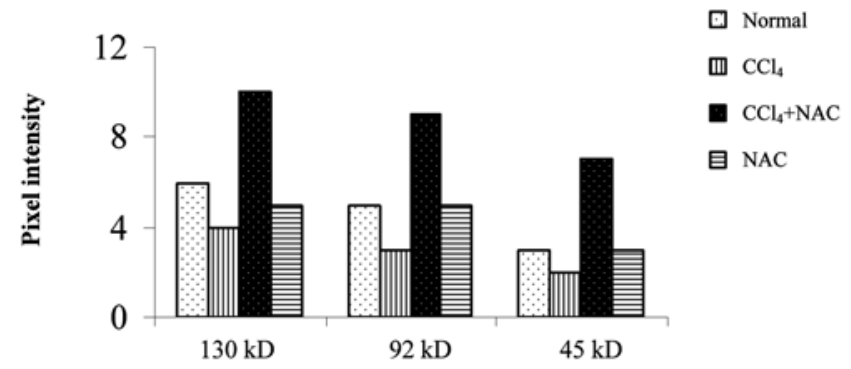

Fig. 4a. Densitometry of multiwell zymogram of kidney samples during $\mathrm{NAC}$ treatment in $\mathrm{CCl}_{4}$ toxicity.

\section{TIMP-1}

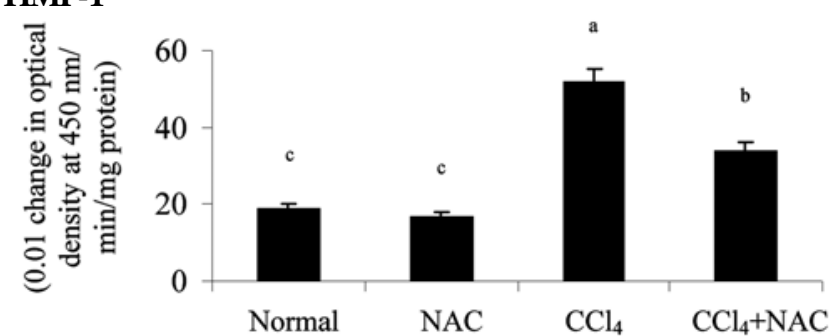

TIMP-2

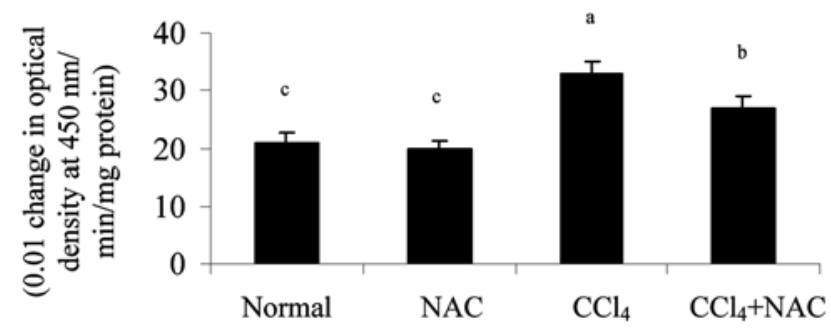

Fig. 5. Levels of TIMPs in liver of NAC and $\mathrm{CCl}_{4}$-treated rats. Each column is mean $\pm \mathrm{SD}$ for 6 rats in each group. Columns that have a different letter (a-c) differ significantly with each other $(\mathrm{p}<0.05$, DMRT $)$.

\section{TIMP-1}

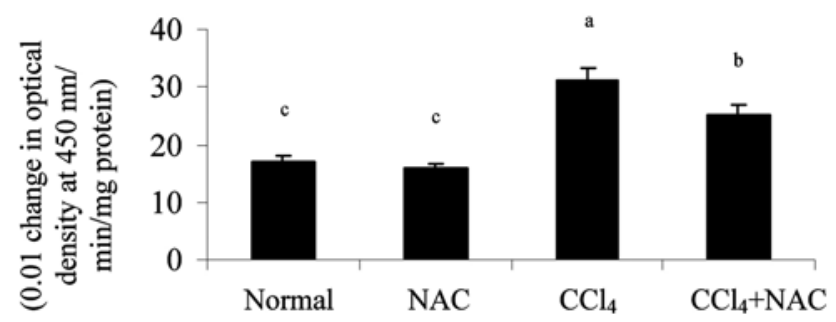

TIMP-2

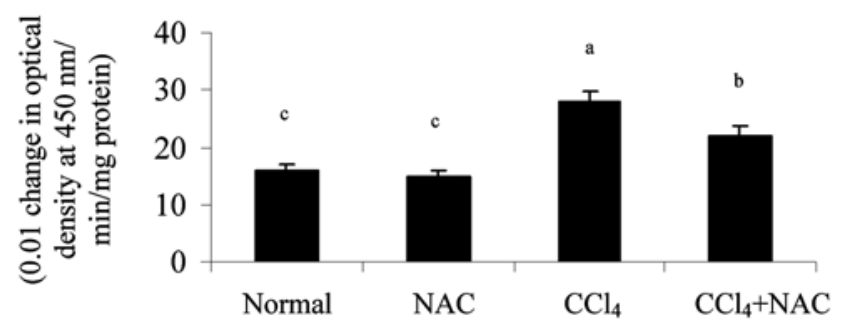

Fig. 6. Levels of TIMPs in kidney of NAC and $\mathrm{CCl}_{4}$-treated rats. Each column is mean $\pm \mathrm{SD}$ for 6 rats in each group. Columns that have a different letter (a-c) differ significantly with each other $(\mathrm{p}<0.05$, DMRT $)$. 
and kidney of normal and experimental groups are shown in Fig. 5 and 6, respectively. A significant increase in the levels of TIMPs was observed in the liver and kidney of rats treated with $\mathrm{CCl}_{4}$. When NAC was administered, their levels decreased significantly. When normal rats were treated with NAC, there was no significant change in the levels of TIMPs.

\section{DISCUSSION}

Hepatic stellate cells (HSCs) are located in the hepatic perisinusoidal spaces (29) and are responsible for excess collagen deposition, fibrosis and cirrhosis in liver injury. Liver injury is associated with activation of these hepatic stellate cells (30). HSCs proliferate and transform to enlarged myofibroblast cells, and these activated HSCs are considered to be the major source of collagenous and non-collagenous matrix proteins which accumulate in fibrotic liver (31). There is an imbalance between synthesis and degradation of matrix components such as collagens, laminin, fibronectin and sulfated proteoglycans in various types of renal diseases and it is closely associated with accumulation of ECM during its progression (32). The progression of renal diseases due to structural remodeling has also been shown to be associated with an imbalance between synthesis and degradation of MMPs/TIMPs (33).

MMPs are a family of proteolytic enzymes that share several structural and functional characteristics, but have different substrate specificities (34). MMP-2 (92 kD) is predominantly secreted by endothelial cells and MMP-9 $(72 \mathrm{kD})$ is the major MMP secreted from macrophages (35). MMP-2 and MMP-9 are often detected by gelatin zymography because of their high-gelatinolytic activity (36). These two gelatinases (MMP-2 and MMP-9) have a gelatin-binding domain inserted between the catalytic domain and active site domain (12).

A decrease in the activities of MMPs in the liver and kidney of rats treated with $\mathrm{CCl}_{4}$ was observed in this study. Treatment with $\mathrm{CCl}_{4}$ generates free radicals that trigger a cascade of events resulting in fibrosis mimicking the oxidative stress that has a fibrogenic effect on hepatic stellate cells (HSCs) (37). Increased ROS production may also be involved in stimulation of excessive matrix production in vivo (38). Matrix metalloproteinases target the various substrates of the ECM, causing their dissolution (39). A decrease in the activities of MMPs in $\mathrm{CCl}_{4}$-treated group signifies end stage fibrosis. A decrease in the MMP activities in progressive stage of liver fibrosis has been reported (8). This decrease could be due to decreased procollagen gene expression and biosynthesis, decreased activation of proMMPs or specific inhibition of native MMPs (8).

The expression and ratio of MMPs/TIMPs are key factors to ECM remodeling (40). TIMP-1 is produced by kupffer cells, HSC and myofibroblasts in liver, but most of it is mainly produced by activated HSCs. TIMP-2 is highly expressed in hepatocytes and kupffer cells, but the main origin is activated HSCs (40). TIMPs are known to bind tightly to particular latent MMPs: TIMP-1 binds tightly to proMMP-9 and TIMP-2 binds tightly to proMMP-2 (12). TIMP-1 could inhibit most of the MMPs by integrating them at a ratio of $1: 1$ to form a complex. The ability of TIMP-2 to integrated MMP-2 is $7 \sim 9$ fold higher than that of TIMP-1 (40). In $\mathrm{CCl}_{4-}$ induced liver fibrosis in rats, an increased expression of TIMPs was observed by us and has also been reported by other researchers $(30,41) . \mathrm{CCl}_{4}$ by producing a large amount of ROS enhances TIMPs generation, which in turn favored collagen deposition by inhibiting MMP activities (42).

Oxidative stress has an important role in the pathogenesis of liver and glomerular fibrosis and decreasing the production of ROS can prevent excess matrix deposition in liver and kidney. NAC administration to $\mathrm{CCl}_{4-}$ treated rats decreased the excessive collagen deposition in the matrix by increasing MMP activities and by decreasing the levels of TIMPs in the liver and kidney. NAC could significantly interfere with the pathophysiology of free radical producing drug induced oxidative stress (19). The result is decreased lipid peroxidation and prevention of liver and kidney damage, progressing towards end fibrotic stage. In addition, the protective effect of some antioxidant compounds on matrix remodeling by maintaining MMPs/TIMPs equilibrium have been reported $(15,16)$.

The overall results of our study confirm the protective effect of NAC in $\mathrm{CCl}_{4}$-induced toxicity in rats by its ability of free radical scavenging and antioxidant properties. NAC exhibits its antifibrogenic activity by increasing MMP activities and decreasing the levels of TIMPs in the liver and kidney of $\mathrm{CCl}_{4}$-treated rats.

\section{ACKNOWLEDGEMENTS}

We gratefully acknowledge UGC for sanctioning the project. The first author is a project fellow in the UGC major project.

\section{REFERENCES}

1. Renner H. 1985. The limited relevance of models used for testing human hepatic diseases and their prevention. In Mechanism of hepatocyte injury and death. Keppler E, 
Popper H, Bianchi L, Reutter W, eds. MTP Press Ltd., Lancaster. p 311-320.

2. Crupi V, Majolino D, Migliardo P, Mondello MR, Germano MP, Pergolizzi S. 2001. FT-IR molecular evidence of liver damage by chemical agents. Vibrational Spec 25: 213-222

3. Recknagel RO, Glende EA Jr, Dolak JA, Waller RL. 1989. Mechanism of carbon tetrachloride toxicity. Pharmacol Ther 43: 139-154.

4. Castro JA. 1984. Mechanistic studies and prevention of free radical cell injury. In Proceedings of IUPHAR. 9th International Congress of Pharmacology. Paton W, Mitchel J, Turner P, eds. McMillan, London. p 243-250.

5. Weber LWD, Boll M, Stampfl A. 2003. Hepatotoxicity and mechanism of action of haloalkanes: Carbon tetrachloride as a toxicological model. Crit Rev Toxicol 33: 105-136.

6. Mauch C. 1998. Regulation of connective tissue turnover by cell-matrix interactions. Arch Dermatol Res 290: S30-S36.

7. Razzaque MS, Kumatori A, Harada T, Taguchi T. 1998. Coexpression of collagens and collagen-binding heat shock protein 47 in human diabetic nephropathy and IgA nephropathy. Nephron 80: 434-443.

8. Arthur MJ. 1990. Matrix degradation in the liver. Sem Liv Diseases 10: 47-55.

9. Eddy AA. 2000. Molecular basis of renal fibrosis. Pediatric Nephrol 15: 290-301.

10. Vincenti MP. 2001. The matrix metalloproteinase (MMP) and tissue inhibitor of metalloproteinase genes. Meth Mol Biol 151: 121-148.

11. Nagase H. 1997. Activation mechanisms of matrix metalloproteinases. Biol Chem 378: 151-160.

12. Kleiner DE, Stetler-Stevenson WG. 1999. Matrix metalloproteinases and metastasis. Cancer Chem Pharmacol 43: S42-S51.

13. Suskind PEH, Hymowitz MH, Lau YH, Atkins HL, Hurewitz AN, Valentine ES, Meek AG, Zucker S. 2003. Increased plasma levels of matrix metalloproteinase- 9 and tissue inhibitor of metalloproteinase-1 in lung and breast cancer are altered during chest radiotherapy. Int $J$ Rad Oncol Biol Phys 56: 1161-1169.

14. Feng-qin D, Hong L, Wei-min C, Jun T, Qun L, Yu R, Fen-Ping Z, Zhe Z. 2004. Effects of pioglitazone on expressions of matrix metalloproteinases 2 and 9 in kidneys of diabetic rats. Chinese Med J 117: 1040-1044.

15. Guo MZ, Li XS, Xu HR, Mei ZC, Shen W, Ye XF. 2002. Rhein inhibits liver fibrosis induced by carbon tetrachloride in rats. Act Pharmacol Sin 23: 739-744.

16. Pavanato A, Tunon MJ, Sanchez-Campos S, Marroni CA, Llesuy S, Gonzalez-Gallego J, Marroni N. 2003. Effects of quercetin on liver damage in rats with carbon tetrachloride-induced cirrhosis. Dig Dis Sci 48: 824-829.

17. Sochman J, Kolc J, Vrana M, Fabian J. 1990. Cardioprotective effects of N-acetylcysteine: the reduction in the extent of infarction and occurrence of reperfusion arrhythmias in the dog. Int J Cardiol 28: 191-196.

18. Miesel R, Zuber M. 1993. Copper-dependent antioxidase defenses in inflammatory and autoimmune rheumatic diseases. Inflammation 17: 283-294.

19. Raza M, Ahmad M, Gado A, Al-Shabanah OA. 2003. A comparison of hepatoprotective activities of aminoguanidine and $\mathrm{N}$-acetylcysteine in rat against the toxic damage induced by azathioprine. Comp Biochem Physiol
Part C 134: 451-456.

20. Flanagan RJ, Meredith TJ. 1991. Use of N-acetylcysteine in clinical toxicology. Am J Med 91: 131S-139S.

21. Remirez D, Commandeur JNM, Groot E, Vermeulen NPE. 1995. Mechanism of protection of lobenzarit against paracetamol-induced toxicity in rat hepatocytes. Eur J Pharmacol Environ Toxicol Pharmacol 293: 301-308.

22. Al-Mustafa ZH, Al-Ali AK, Qaw FS, Abdul-Cader Z. 1997. Cimetidine enhances the hepatoprotective action of $\mathrm{N}$-acetylcysteine in mice treated with toxic doses of paracetamol. Toxicology 121: 223-228.

23. Varma PS, Aruna K, Rukkumani R, Menon VP. 2004. Alcohol and thermally oxidized PUFA induced oxidative stress: role of $\mathrm{N}$-acetyl cysteine. Italian $\mathrm{J}$ Biochem 53: $10-15$.

24. Akila GV, Rajakrishnan V, Viswanathan P, Rajashekaran KN, Menon VP. 1998. Effects of curcumin on lipid profile and lipid peroxidation status in experimental hepatic fibrosis. Hepatol Res 11: 147-157.

25. Sudhakaran PR, Ambili M. 1998. Assay of matrix metalloproteinases in substrate impregnated gels in multiwells. Indian J Biochem Biophys 35: 317-320.

26. Ambili M, Radhakrishna PM, Sudhakaran PR. 1997. Characteristics of $60 \mathrm{~K}$ gelatinase involved in rat mammary gland involution. Indian J Biochem Biophys 34: 347-353.

27. Baragi VM, Shaw BJ, Renkiewicz RR, Kuipers PJ, Welgus HG, Mathrubutham M, Cohen JR, Rao SK. 2000. A versatile assay for gelatinases using succinylated gelatin. Matrix Biol 19: 267-273.

28. Iype T, Jayasree K, Sudhakaran PR. 2001. Modulation of alpha2 beta1 integrin changes during mammary gland development by beta-oestradiol. Biochim Biophys Acta 1499: 232-241.

29. Loreal O, Levavasseur F, Fromaget C, Gros D, Guillouzo A, Clement B. 1993. Cooperation of Ito cells and hepatocytes in deposition of an extracellular matrix in vitro. Am J Pathol 143: 538-544.

30. Iredale JP, Benyon RC, Pickering J, McCullen M, Northrop M, Pawley S, Hovell C, Arthur MJ. 1998. Mechanisms of spontaneous resolution of rat liver fibrosis. Hepatic stellate cell apoptosis and reduced hepatic expression of metalloproteinase inhibitors. J Clin Invest 102: 538-549.

31. Lichtinghagen R, Steinmetz C, Penle B, Breitenstein K, Seifert T, Bocker KHW. 1999. Matrix metalloproteinases in liver and serum in chronic active hepatitis $\mathrm{C}$ and $\mathrm{HCV}$ induced cirrhosis. Hepatol Res 14: 119-134.

32. Eddy AA, Ho GC, Thorner PS. 1992. The contribution of antibody-mediated cytotoxicity and immune-complex formation to tubulointerstitial disease in passive Heymann nephritis. Clin Immunol Immunopathol 62: 42-55.

33. Johnson RJ. 1994. The glomerular response to injury: Progression or resolution? Kidney Int 45: 1769-1782.

34. Nagase H, Woessner JF. 1999. Matrix metalloproteinases. J Biol Chem 274: 21491-21494.

35. Nguyen M, Arkell J, Jackson C. 2000. Activated protein kinase $\mathrm{C}$ directly activates human endothelial gelatinase A. J Biol Chem 275: 9095-9098.

36. Okada Y, Gonoji Y, Naka K, Tomita K, Nakanishi I, Iwata K, Yamashita K, Hayakawa T. 1992. Matrix metalloproteinase 9 (92 kD gelatinase/type IV collagenase) from HT 1080 human fibrosarcoma cells. Purification and activation of the precursor and enzymic properties. J Biol Chem 267: 21712-21719. 
37. Poli G. 2000. Pathogenesis of liver fibrosis: role of oxidative stress. Mol Aspects Med 21: 49-98.

38. Tsukamoto H, Rippe R, Niemela O, Lin M. 1995. Roles of oxidative stress in activation of kupffer and Ito cells in liver fibrogenesis. J Gastroenterol Hepatol 10: S50-S53.

39. Hidalgo M, Eckhardt SG. 2001. Development of matrix metalloproteinase inhibitors in cancer therapy. J Natl Cancer Inst 93: 178-193.

40. Xu GF, Li PT, Wang XY, Jia X, Tian DL, Jiang LD, Yang JX. 2004. Dynamic changes in the expression of matrix metalloproteinases and their inhibitors, TIMPs, dur- ing hepatic fibrosis induced by alcohol in rats. World $J$ Gastroenterol 10: 3621-3627.

41. Hernández-Muñoz R, Díaz-Muñoz M, Suárez-Cuenca JA, Trejo-Solís C, López V, Sánchez-Sevilla L, Yáñez L, De Sánchez VC. 2001. Adenosine reverses a preestablished $\mathrm{CCl}_{4}$-induced micronodular cirrhosis through enhancing collagenolytic activity and stimulating hepatocyte cell proliferation in rats. Hepatology 34: 677-687.

42. Arthur MJ. 2000. Fibrogenesis II. Metalloproteinases and their inhibitors in liver fibrosis. Am J Physiol Gastrointest Liver Physiol 279: G245-G249.

(Received January 31, 2009; Accepted March 18, 2009) 